\title{
Enzyme Substrates Protective Encapsulation within Polymeric Microspheres
}

\author{
Joanna Zajda ${ }^{1,2}$, Agnieszka M. Jastrzębska ${ }^{3}$, Andrzej R. Olszyna ${ }^{3}$, \\ Elżbieta Malinowska ${ }^{2}$, Agata Michalska \\ ${ }^{1}$ University of Warsaw, Faculty of Chemistry, Warsaw, Poland \\ ${ }^{2}$ Warsaw University of Technology, Faculty of Chemistry, Warsaw, Poland \\ ${ }^{3}$ Warsaw University of Technology, Faculty of Materials Engineering, Warsaw, Poland \\ Email: agatam@chem.uw.edu.pl
}

Received June 13, 2013; revised July 14, 2013; accepted August 15, 2013

Copyright (C) 2013 Joanna Zajda et al. This is an open access article distributed under the Creative Commons Attribution License, which permits unrestricted use, distribution, and reproduction in any medium, provided the original work is properly cited.

\begin{abstract}
Determination of enzymes activity is an important task of analytical and biomedical oriented fluorimetry. Despite of a long track record of application, there is still some room for improvements in this field. In the case of hydrolases, spontaneous decomposition of substrate leads to substantial errors in determination of enzyme activity. An innovative and effective approach is proposed allowing protection of enzyme substrate within the lipophilic moiety of polyacrylate microspheres. It is shown that the introduction of substrate into microspheres is not only an effective method of prevention of unwanted spontaneous process, but also does not disturb the availability of substrate for enzymatic hydrolysis. The effect of presence of proteins in the sample on fluorimetric responses was studied. In contrary to previous studies related to application of lipophilic polymers in biomedical analysis, it is shown that the presence of bovine serum albumins enhances the sensitivity of fluorimetric determination. It is shown that this surprising effect is related to adsorption of proteins on the microspheres surface and change of surface charge of polymer.
\end{abstract}

Keywords: Enzyme Substrate Encapsulation; BSA; Lipase; Polyacrylate Microspheres

\section{Introduction}

Analytical procedures used for assessment of enzymes activity often take advantage of substrates that in course of enzymatic reactions which are converted to fluorescent species. Thus the intensity of fluorescence emission can be related to the enzymatic activity within the sample. This approach, however, can be hindered by the spontaneous reactions of enzymeless substrate decomposition leading to the formation of a fluorescent product. This effect was observed, e.g. for coumarines derivatives used as substrates [1-3]. Occurrence of spontaneous decomposition, especially priori analysis, can result in false elevated results of determination; affecting also the sensitivity of determination. Even if under normal conditions, the rate of spontaneous process is low, in the sufficiently long time scale (as during substrate storage) or in the case of even occasional contact with the environment promoting the occurrence of spontaneous reaction, the effect of decomposition process can be quite substantial. Thus this process can affect, apart from causing analysis imprecision, the cost of analysis as usually substrates are relatively expensive. It seems that the most possible substrates prone to such decomposition are the substrates of hydrolases enzymes, as the enzymatic process is in chemical principles the same as spontaneous one. An efficient method of protection of the enzyme substrate from unwanted spontaneous process, yet not affecting substantially activity during enzymatic reaction, can be of interest as it can potentially lead both to economic and analytical improvements. The best option would be if the applied protocol can offer also additional benefits, e.g. it can improve the sensitivity of enzyme activity determination.

Polymeric moiety, including polyacrylate, seems to be a good candidate to shield the sensitive enzyme substrate from unwanted spontaneous processes. The applicability of these systems for fluorimetirc analysis is also well proven [4-14].

A relatively simple solution, able to meet at least in theory, the above stated requirements for shielding material, is polymeric microspheres [15], especially relatively easy to prepare polyacrylate microspheres. The simple method of microspheres preparation, applying common 
monomers, is a clear advantage. Moreover, due to small size and favorable surface area to size ratio, microspheres are proven to be good candidates for fluorimetric miniature sensors [e.g. 15,16]. Last but not least, lipophilic character of the polymer can result in sufficient protection and/or can be useful to create an enzyme favorable reaction microenvironment. However, the known slow diffusion of species within the polyacrylate matrix $[17,18]$ can set limitats on the proposed approach.

The aim of this study was to experimentally verify the possibility of protective encapsulation of substrate (yielding in course of reaction a fluorescent product) within the polyacrylate microsphere. As a model system, poly(nbutylacrylate) microspheres were chosen and the possibility of protective encapsulation of lipase from porcine pancreas fluorogenic substrate: 4-methylumbelliferyl oleate (4-MUO) was studied. The limited solubility of this substrate in aqueous samples (which does not limit spontaneous hydrolysis) was additional motivation for incurporation of this compound within polymeric microspheres moiety. The effect of inclusion of 4-MUO within the microspheres on its stability was compared with unprotected substrate. Different factors affecting sensitivity of responses are discussed.

\section{Experimental}

\subsection{Apparatus}

Varian Cary-Eclipse Fluorescence Spectrophotometer were used for all fluorimetric measurements. All measurements were performed using microtiter 96-well plate. Fluorescence emission spectra were recorded in the wavelength range of $400-600 \mathrm{~nm}$ using excitation wavelength $330 \mathrm{~nm}$. The slits used were $5 \mathrm{~nm}$ both for excitation and emission, while the detector voltage, unless otherwise stated, was maintained between 800 and $900 \mathrm{~V}$.

Zetasizer NanoZS (Malvern Instruments) with the use DLS (dynamic light scattering), NIBS (Non-Invasive Back Scatter) and M3-PALS technology were used to determine particles size and Zeta potentials. The measurements were conducted after 2 seconds of stabilization in $25^{\circ} \mathrm{C}$, for each measurement 10 repetitions were carried out.

\subsection{Reagents}

Tetrahydrofuran (THF), n-butyl acrylate (nBA), 1,6-hexanedioldiacrylate (HDDA), 2,2-dimethoxy-2-pheny-lacetophenone (DMPP), poly(vinyl alcohol) (PVA), 4-methylumbelliferyl oleate (4-MUO), tris (hydroxymethyl) aminomethane and albumin from bovine serum (BSA), lipase (EC 3.1.1.3) from porcine pancreas (Type II) were from Sigma (Germany).

All other chemicals used were of analytical grade and were obtained from POCh (Gliwice, Poland). Doubly distilled and freshly deionised water was used throughout this work (resistance 18.2 M $\mathrm{cm}$, Milli-Qplus, Millipore, Austria).

\subsection{Synthesis of Poly(n-Butyl Acrylate) Microspheres}

The synthesis of poly(n-butyl acrylate) microspheres was carried out according to the method of Hall, et al. [16], with some modifications. A mixture of n-butyl acrylate (nBA) $(480 \mu \mathrm{l})$, HDDA $(220 \mu \mathrm{l})$ as cross-linker and DMPP (15 mg) as initiator was prepared using an ultrasound probe for $3 \mathrm{~min}$ (Heilsher UP200S, cycle: 0.5; amplitude 50\%). The mixture was then dispersed in $5 \mathrm{ml}$ of aqueous $1 \%(\mathrm{w} / \mathrm{v})$ poly(vinyl alcohol) solution (PVA), using again the ultrasound probe (for 5 minutes and amplitude $70 \%$ ) and was immediately photopolymerized. The polymerization step was carried out using UV light (peak output $320 \mathrm{~nm}$ ) under argon for 5 min using vigorous stirring of the emulsion.

Following polymerization the solid fraction was separated by centrifugation at $5800 \mathrm{rpm}$ for $10 \mathrm{~min}$. The polymeric spheres obtained were washed with small amount of water, again centrifuged and dispersed in $5 \mathrm{ml}$ of aqueous $1 \%$ PVA.

\subsection{4-MUO Solutions and 4-MUO Loaded Microspheres}

4-Methylumbelliferyl oleate solutions of different concentrations were prepared, directly before use, by dissolving 4-MUO in THF, if 4-MUO solution was used directly (i.e. without microspheres), this solution was added to water based samples.

To introduce 4-MUO to the microsphere a simple absorption procedure [16] was applied. Unless otherwise stated, microspheres were prepared directly before use. To $1 \mathrm{ml}$ of poly(n-butylacrylate) microspheres suspendsion $0.6 \mathrm{ml}$ of THF based solution of 4-MUO was added (different concentrations of 4-MUO solutions, were applied as indicated in the text, keeping the volume proportion of microspheres suspension to THF solution constant), and the contents was well mixed. Then the mixture was left for 24 hours at $4^{\circ} \mathrm{C}$. After this time, the microspheres were separated by centrifugation at $5800 \mathrm{rpm}$ for $15 \mathrm{~min}$, washed well with water and again centrifugated to finally be dispersed in $1 \mathrm{ml}$ of $1 \%$ PVA. Thus obtained 4-MUO loaded microspheres (4-MUO-microspheres) were kept in the fridge until use $(<1 \mathrm{~h})$. The different loading of microspheres with 4-MUO achieved is expressed giving the total amount of 4-MUO present in THF solutions used to introduce substrate per $1 \mathrm{ml}$ of microspheres suspension (i.e. the effectively of incorporation is not taken into account while expressing loading of microspheres with 4-MUO). 
The effectiveness of 4-MUO incorporation was estimated comparing the fluorescence intensity of the loaded microspheres compared to the fluorescence intensity of supernatant obtained after centrifugation of the loaded microspheres. In this experiment, $20 \mu \mathrm{l}$ of microspheres or supernatant solutions following incorporation performed for 4-MOU concentrations $0.2,0.4$ or $0.6 \mathrm{mg} / \mathrm{ml}$, respectively were mixed with $50 \mu$ of enzyme solution of concentration $2 \mathrm{mg} / \mathrm{ml}$ and $180 \mu \mathrm{l}$ of $10 \mathrm{mmol} / \mathrm{dm}^{3}$ TRIS buffer, the intensity was measured after 30 minutes (detector voltage was set to $1000 \mathrm{~V}$ ).

\subsection{Enzyme Stock Solution/Enzyme Activity}

The enzyme exhibited limited solubility in water, thus its stock solution was prepared every day before a series of experiments, using the following procedure: $10 \mathrm{mg}$ of lipase was mixed with $5 \mathrm{ml}$ of TRIS buffer solution (10 $\mathrm{mmol} / \mathrm{dm}^{3}, \mathrm{pH} \mathrm{7.6)}$ and left for $30 \mathrm{~min}$ with occasional stirring. Thus obtained suspension was gently centrifuged at $2900 \mathrm{rpm}$ for $5 \mathrm{~min}$. The supernatant was collected and used as a stock solution and it was kept until use in fridge.

The assessment of enzyme activity for above mentioned solution was performed using titration procedure adapted from [19]. $2 \mathrm{ml}$ of olive oil was dispersed in $2 \mathrm{ml}$ of $1 \%$ PVA solution and $16 \mathrm{ml}$ of deionized water using ultrasound probe. $\mathrm{pH}$ of aliquot of this suspension was adjusted with TRIS buffer, the mixture was homogenized using ultrasound probe, $3 \mathrm{ml}$ of thus obtained suspension was mixed with $3 \mathrm{ml}$ of lipase solution prepared as described above and $1 \mathrm{ml}$ of TRIS buffer. Thus obtained sample was incubated for $6 \mathrm{~h}$ in water bath of controlled temperature equal to $37^{\circ} \mathrm{C} \pm 0.5^{\circ} \mathrm{C}, 1 \mathrm{ml}$ portion of the sample was kept for $6 \mathrm{~h}$ in fridge. After this time, both solutions were combined and $3.0 \mathrm{ml}$ of ethyl alcohol (96\%) was added to stop the enzymatic reaction. The sample was titrated with $\mathrm{NaOH}$ solution in the presence of tymolophtalein. The determined activity of the lipase was equal to $0.074 \pm 0.006 \mathrm{U} / \mathrm{mg}$, this value was used through the work.

\subsection{The Dependence of Fluorescence Emission Intensity on Change of Lipase Activity in Solution}

The dependences were recorded on microtitration plates: $30 \mu \mathrm{l}$ of microspheres loaded with 4-MUO were mixed with appropriate amount of lipase solution (prepared as described above in TRIS buffer) ranging from 0 to $100 \mu \mathrm{l}$ (stock solution containing $2 \mathrm{mg} / \mathrm{ml}$ ) and TRIS buffer was added up to $300 \mu \mathrm{l}$. After 40 minutes in room temperature, the fluorescence emission spectra were recorded (detector voltage was set to $800 \mathrm{~V}$ ).

To evaluate the effect of BSA $75 \mu$ l of lipase solution in TRIS buffer $(2 \mathrm{mg} / \mathrm{ml})$ was mixed in well with $30 \mu \mathrm{l}$ of microspheres loaded with 4-MUO (1.8 mg 4-MUO/ $\mathrm{ml}$ ) and with $100 \mu \mathrm{l}$ of BSA solution in TRIS buffer of chosen concentration (either $0.5 \mathrm{mg} / \mathrm{ml}, 1.5 \mathrm{mg} / \mathrm{ml} ; 3$ $\mathrm{mg} / \mathrm{ml} ; 5 \mathrm{mg} / \mathrm{ml}$ or $10 \mathrm{mg} / \mathrm{ml}$ ) and TRIS buffer was added up to $300 \mu \mathrm{l}$. After 40 minutes in room temperature, the fluorescence emission spectra were recorded (detector voltage was set to $700 \mathrm{~V}$ ).

To evaluate the effect of calcium or sodium ions, $50 \mu \mathrm{l}$ of lipase solution in TRIS buffer $(2 \mathrm{mg} / \mathrm{ml})$ was mixed in well with $30 \mu \mathrm{l}$ of microspheres loaded with 4-MUO (1.8 $\mathrm{mg} / \mathrm{ml}$ ) and with $30 \mu \mathrm{l}$ of calcium or sodium chloride solution of chosen concentration (either $1 \mathrm{~mol} \cdot \mathrm{dm}^{-3}, 5 \times$ $10^{-1} \mathrm{~mol} \cdot \mathrm{dm}^{-3}, 10^{-1} \mathrm{~mol} \cdot \mathrm{dm}^{-3}, 5 \times 10^{-2} \mathrm{~mol} \cdot \mathrm{dm}^{-3}, 10^{-2}$ $\mathrm{mol} \cdot \mathrm{dm}^{-3}, 5 \times 10^{-3} \mathrm{~mol} \cdot \mathrm{dm}^{-3}, 10^{-3} \mathrm{~mol} \cdot \mathrm{dm}^{-3}$ ) and TRIS buffer was added up to $300 \mu \mathrm{l}$. After 40 minutes in room temperature, the fluorescence emission spectra was recorded (detector voltage was set to $700 \mathrm{~V}$ ).

For each experiment, two samples were prepared and assessed, the mean fluorescence intensity was used to construct graphs.

\subsection{Enzymatic 4-MUO Hydrolysis in Time}

For kinetic measurement in well of microtitration plate, $30 \mu \mathrm{l}$ of microspheres loaded with 4-MUO (0.6 or 0.4 $\mathrm{mg} / \mathrm{ml}$ ) was mixed with $50 \mu \mathrm{l}$ of enzyme solution in TRIS ( $2 \mathrm{mg} / \mathrm{ml})$ and TRIS was added up to $250 \mu \mathrm{l}$. The change of fluorescence intensity was measured each 5 minutes for total $1 \mathrm{~h}$ time (detector voltage was set to 900 $\mathrm{V})$.

\subsection{Stability of 4-MUO in Solutions or in Microspheres in Time}

To evaluate the effect of spontaneous substrate hydrolysis either in solution or in microspheres: $50 \mu \mathrm{l}$ of suspension of microspheres loaded with 4-MUO (either 0.6 $\mathrm{mg} / \mathrm{ml}$ or $1.2 \mathrm{mg} / \mathrm{ml}$ ) or $50 \mu \mathrm{l}$ of $4-$ MUO solution in THF $(1 \mathrm{mg} / \mathrm{ml})$ were introduced to Eppendorf vials and $450 \mu \mathrm{l}$ of one of following solutions was added: $0,1 \mathrm{~mol} / \mathrm{dm}^{3}$ $\mathrm{HCl}, 0.1 \mathrm{~mol} / \mathrm{dm}^{3} \mathrm{NaOH}, 0.01 \mathrm{~mol} / \mathrm{dm}^{3}$ TRIS buffer $\mathrm{pH}$ $=7.6$ and the contents of the vial was mixed. Immutably after mixing $10 \mu \mathrm{l}$ of each sample was taken, placed in microtitration plate and diluted with $240 \mu$ TRIS buffer and the intensity of fluorescence was measured $(\mathrm{t}=0)$. The prepared mixtures were stored in room temperature or in fridge and the fluorescence intensity was measured periodically in the same way as for $\mathrm{t}=0$.

For each determination three samples were prepared and assessed, the mean fluorescence intensity was used to construct graphs.

\subsection{Evaluation of Microspheres Size and Zeta Potential}

Microspheres size and Zeta potential were determined in 
TRIS buffer solution ( $\mathrm{pH}=7.6$ ). The samples used were A) polymerized microspheres (as used for introduction of substrate, i.e. before contact with water/THF mixture); B) loaded with 4-MOU from solution containing $1.8 \mathrm{mg} / \mathrm{ml}$ of substrate; C) microspheres loaded with 4-MOU from solution containing $1.8 \mathrm{mg} / \mathrm{ml}$ of substrate, then left in contact with BSA $0.5 \mathrm{mg} / \mathrm{ml}$ for 40 minutes.

\section{Results and Discussion}

Application of enzyme substrate that in course of enzymatic reaction is converted to fluorescent compound allows relatively easy assessment of enzyme activity. However, the sensitivity of determination can be affected by spontaneous, enzymeless, reactions, e.g. hydrolysis, yielding fluorescent compound. Thus preventing occurrence of spontaneous generation of fluorescent compound, but with no significant effect on availability of the substrate for enzymatic reaction, is challenging. Additional requirement for protection system introduced is to assure interface conditions in which the enzyme (e.g. present in water solution) can react with the substrate that is predominantly soluble in organic solvents. A polymeric microsphere seems to be a suitable choice — due to high surface to volume ratio, the interface is relatively large. Moreover, the microsphere surface is permeable, thus allows ions/molecules exchange between the relatively lipophilic inside of the sphere and outside water based solution. This has been proven by numerous research on polyacrylate based ion-selective electrodes [e.g. $17,18]$ as well as on polymeric microspheres $[4,6,16]$.

Incorporation of molecules into the polymeric microspheres, in principle, can be achieved either during polymerization $[4,6]$ or afterwards by absorption of molecules to ready spheres, e.g. during microspheres contact with mixed water/THF based solution containing the molecule of choice $[15,16]$. The latter, relatively simple, method was applied to avoid preliminary (from the point of view microsphere formation) possible contact of 4-MUO with water solution. The fluorescence emission spectra obtained for microspheres loaded with 4-MUO as well as for supernatant from the incorporation process shown maximum of emission intensity at about $450 \mathrm{~nm}$, which is close to typical wavelength of enzymatic hydrolysis product, Figure 1.

The comparison of the fluorescence emission recorded for microspheres and for supernatant solution, for different amounts of 4-MUO being introduced to microspheres, reveals that the ratio of fluorescence intensity for microspheres containing sample to the sum of fluorescence intensities of microspheres suspension and supernatant is constant for tested amounts of 4-MUO present in the solution used for microspheres loading. It is close to $70 \%$, suggesting that most of the reagent used is included in the spheres. Taking into account simplifying assumption

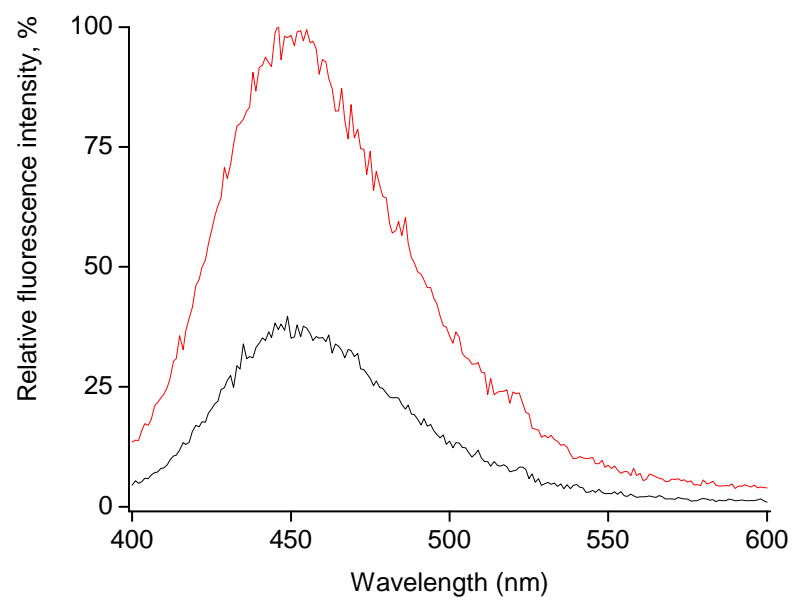

Figure 1. Fluorescence emission spectra of 4-MUO loaded microspheres $(0.6 \mathrm{mg} / \mathrm{ml})$ (red line) and supernatant from substrate introduction procedure (black line) recorded after 40 minutes contact with $50 \mu$ l solution containing $1.5 \mathrm{U} / \mathrm{ml}$ of lipase.

that 4-MUO present in the solution and in the microspheres is in similar way available for enzymatic hydrolysis, the effectiveness of incorporation can be estimated to be independent of the concentration of 4-MUO in solution (within the tested 4-MUO concentration range). It seems possible that the process of incorporation is ruled by partition equilibrium prevailing between the microspheres and solution. Probably it is also to some extent affected by the diffusion of introduced 4-MUO from the surface to the inside of the microsphere, however as incorporation occurs in water THF mixture, where swelling of microspheres is highly possible, these effects are less pronounced during this step.

\subsection{Spontaneous Hydrolysis of 4-MUO (in Microspheres and in Solution)}

The main motivation for encapsulation of enzymatic reaction substrate within the polymeric microspheres is to prevent spontaneous hydrolysis of this compound, yielding formation of fluorescent species in solution. Thus the effect of storage conditions, in the absence of enzyme, on stability of 4-MUO was studied looking at the formation of fluorescence attributed to spontaneous hydrolysis product, both for 4-MUO in solution and introduced into microspheres, Figure 2.

As it can be seen in Figure 2(a), even short contact (the first measurement of fluorescence intensity was performed about 5 minutes after mixing of sample constituents, on the day experiment was started) of 4-MUO with alkaline solution (in the absence of lipase) leads immediately to pronounced fluorescence intensity of solution. A similar effect was observed in room temperature and when samples were stored at $4^{\circ} \mathrm{C}$, clearly suggesting that predominantly alkaline $\mathrm{pH}$ conditions are contributing to 


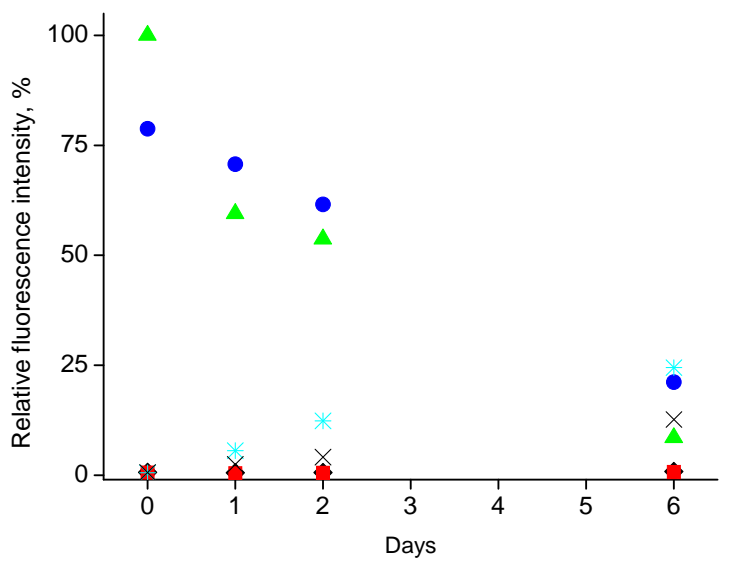

(a)

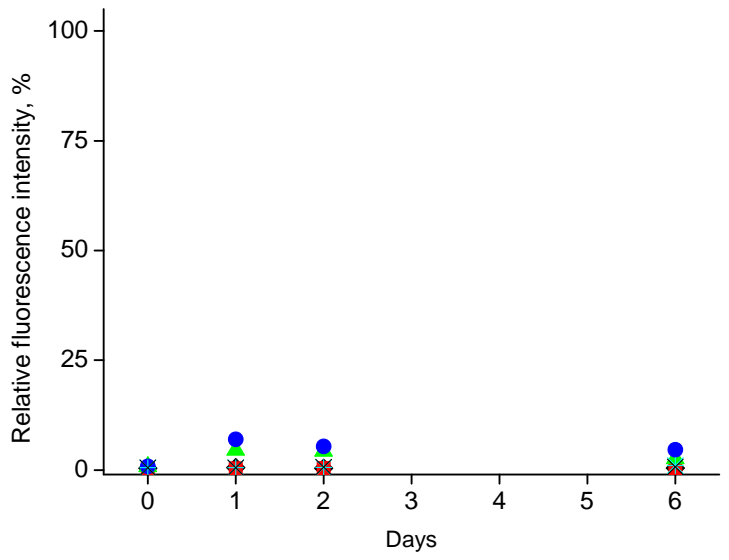

(b)

Figure 2. Effect of storage conditions on fluorescence emission resulted from spontaneous (enzymeless) hydrolysis studied for mixtures a) 4-MUO in THF solution $(1 \mathrm{mg} / \mathrm{ml})$ or b) 4-MUO encapsulated in poly(n-butyl acrylate) microspheres $(1.2 \mathrm{mg} / \mathrm{ml})$ as a function of time. Fluorescence intensity was measured for samples kept under different conditions: ( $\diamond) 0.1 \mathrm{M} \mathrm{HCl}, \mathrm{t}=25^{\circ} \mathrm{C}$, (口) $0.1 \mathrm{M} \mathrm{HCl}, \mathrm{t}=4^{\circ} \mathrm{C},(\triangle)$ $0.1 \mathrm{M} \mathrm{NaOH}, \mathrm{t}=25^{\circ} \mathrm{C}$, (O) $0.1 \mathrm{M} \mathrm{NaOH}, \mathrm{t}=4^{\circ} \mathrm{C},(*) 0.01$ M TRIS-HCI buffer pH 7.6, $\mathrm{t}=25^{\circ} \mathrm{C},(\times) 0.01 \mathrm{M}$ TRIS-HCI buffer $\mathrm{pH}$ 7.6, $\mathrm{t}=4^{\circ} \mathrm{C}$.

the observed effect.

Contact of 4-MUO with TRIS buffer of $\mathrm{pH} 6$ (conditions close to those of lipase activity assessment) or in $\mathrm{HCl}$ solution was leading to increase of fluorescence intensity in time as well. It was found that 4-MUO in solution is relatively most stable when it is stored in acidic conditions (regardless temperature) or in TRIS buffer at $4^{\circ} \mathrm{C}$, Figure 2(a) - under this condition the lowest fluorescence intensity signals were observed.

The above presented results clearly show that spontaneous hydrolysis of 4-MUO is leading to formation of fluorescent products even in the absence of enzyme in solution. Moreover depending on conditions the magnitude of the effect is different, and in some cases even accidental contact of 4-MOU with alkaline solution can significantly deteriorate analytical usefulness of substrate. It should be stressed that degradation of coumarin derivatives has been previously demonstrated by Nyfeler, et al. [3]. In this work it was observed that commercially available 4-methylumbelliferone acyl esters spontaneously hydrolyze at pH 8.8 and higher. Moreover, instability of these compounds even under lipase assay optimal condition was also described [20,21].

On the other hand, Figure 2(b), incorporation of 4MUO within the poly(n-butylacrylate) microspheres effectively prevents occurrence of spontaneous, enzymeless, hydrolysis. It should be stressed that neither in highly alkaline solutions, nor in longer time scale (6 days), regardless temperature applied formation of fluorescent compounds was observed only to small exten (5\% of the highest fluorescence intensity of 4-MUO in solution). This effect clearly shows the applicability and high analytical potential of proposed approach.

\subsection{Enzymatic Driven Hydrolysis of 4-MUO Incorporated in Microspheres}

The applied protocol of 4-MUO introduction into the poly(n-butylacrylate) microspheres in principle allows incorporation of different amount of fluorogenic substrate, yielding in tunable sensitivity of fluorescence signal for given lipase activity. Indeed, as shown in Figure 3(A) changing concentration of 4-MUO in solution used during substrate introduction to microspheres, results in different intensity of fluorescence emission, for all other parameters (enzyme activity, reaction time and conditions) constant. Thus using the same amount of microspheres, different sensitivity of enzyme activity determination can be achieved. Indeed as shown in Figure 3, depending on the amount of 4-MUO present in the solution used for substrate incorporation in the microspheres, different slope of dependences of fluorescence intensity on enzyme activity was obtained. It should be stressed

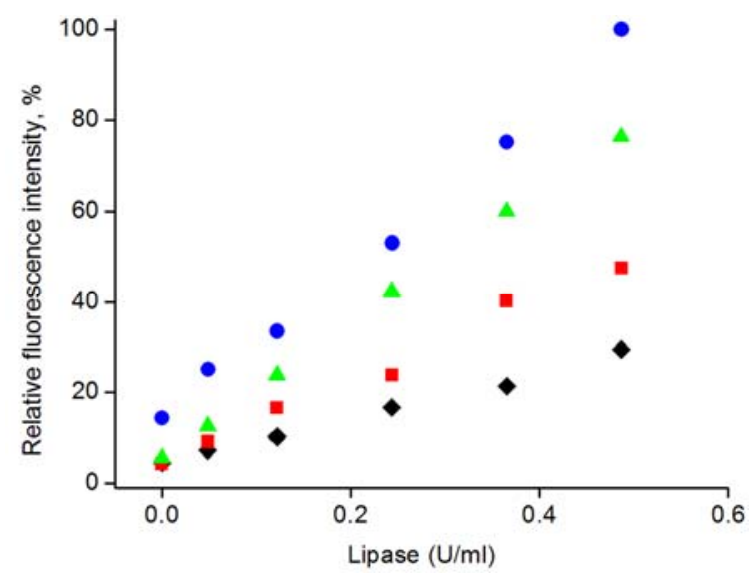

Figure 3. Calibration curves obtain with the use of microspheres with various amount of encapsulated 4-MUO: $(\diamond)$ $0.4 \mathrm{mg} / \mathrm{ml},(\square) 0.6 \mathrm{mg} / \mathrm{ml},(\triangle) 1.2 \mathrm{mg} / \mathrm{ml},(\bigcirc) 1.8 \mathrm{mg} / \mathrm{ml}$. 
that regardless the amount of 4-MUO introduced to the microspheres all dependencies recorded were linear within tested enzyme activities $\left(\mathrm{R}^{2}\right.$ of all lines $\left.>0.99\right)$. For the lowest concentration of 4-MUO used for incurporation, $0.4 \mathrm{mg} / \mathrm{ml}$, the slope of dependence was also the lowest among tested.

Even relatively small increase of 4-MUO concentration during microspheres loading from 0.4 to $0.6 \mathrm{mg} / \mathrm{ml}$, resulted in pronounced increase of slope of the dependence (slope increased by factor 2). Application of yet higher 4-MUO concentration in solution used to introduction of this compound to the microspheres $(1.2 \mathrm{mg} / \mathrm{ml})$ resulted in linear dependence of fluorescence intensity vs. enzyme activity in solution of 1.5 times higher slope compared to microspheres loaded with $0.6 \mathrm{mg} / \mathrm{ml}$ of 4-MUO, while the linear response range was not affected. Further increase of 4-MUO concentration in solution used to loead poly(n-butylacrylate) microspheres to 1.8 $\mathrm{mg} / \mathrm{ml}$ did not result in significant increase in sensitivity of fluorescence intensity vs. change of lipase activity, however the obtained dependence was shifted on Y-axis towards higher fluorescence activities, resulting in higher offset of obtained dependence. This result can suggest that some of the incorporated 4-MUO is loosely trapped within the outer region of the microsphere to be readily released upon contact with sample solution.

From the results presented in Figure 3, it is clear that amount of 4-MUO introduced into the microspheres can be easily used to tune sensitivity of determination, which is crucial parameter for analytical performance of microspheres.

Figure 4 presents the change of the fluorescence intensity in time, recorded for microspheres loaded with 4-MUO from either $0.6 \mathrm{mg} / \mathrm{ml}$ or $0.4 \mathrm{mg} / \mathrm{ml}$ solution of substrate. In both cases a linear increase of fluorescence intensity in time was observed, suggesting that in both

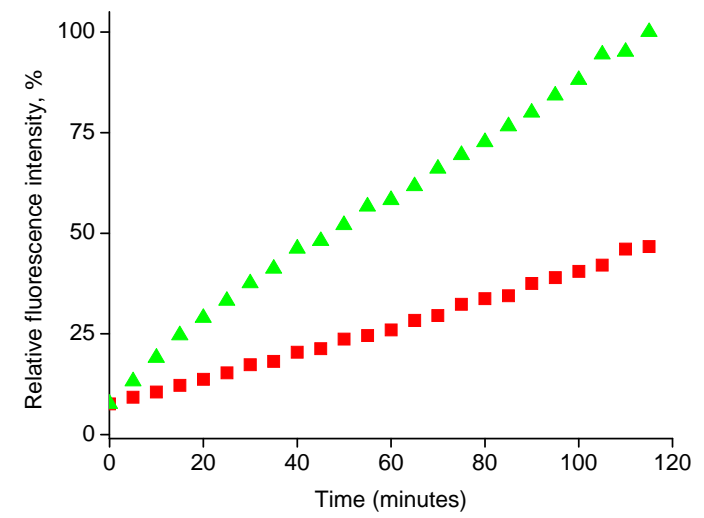

Figure 4. Changes in fluorescence intensity at $\lambda_{\mathrm{em}}=450 \mathrm{~nm}$ during enzymatic reaction for 4-MUO introduced to microspheres from solution containing (অ) $0.4 \mathrm{mg} / \mathrm{ml}$ or $(\triangle)$ $0.6 \mathrm{mg} / \mathrm{ml}$, during contact with $50 \mu \mathrm{l}$ solution containing 1.5 $\mathrm{U} / \mathrm{ml}$ of lipase. (Final lipase activity in experiment $\mathbf{0 . 0 2 9 6}$ $\mathrm{U} / \mathrm{ml})$. cases there is an excess of substrate accessible for followed reaction time. It should be stressed that the slope of the fluorescence intensity vs. time dependence for microspheres loaded with 4-MOU from solution containing $0.6 \mathrm{mg} / \mathrm{ml}$ of substrate was two times higher compared to microspheres loaded with 4-MOU from solution containing $0.4 \mathrm{mg} / \mathrm{ml}$. The results presented in Figure 4 suggest that during the experiment 4-MUO is continuously released, with constant rate, from the microsphere and is transformed by enzyme to fluorescent product.

\subsection{Effect of Bovine Serum Albumin}

In principle, one of the additional benefits resulting from inclusion of 4-MUO within the microspheres is possibility of tailored modification of the microspheres surface to further enhance the sensitivity of the enzyme activity determination. Earlier studies [22,23], related to oil-water interface reaction of porcine pancreatic lipase have shown that the presence of low concentration of BSA is able to protect lipase from denaturation. However, at higher concentrations of BSA $(2.75 \mathrm{mg} / \mathrm{ml} \mathrm{[24])} \mathrm{the}$ reduction of lipase activity was observed and attributed to decreased lipase binding at the interface [22-26].

Taking into account these reports, the effect of BSA presence in sample solutions was studied for 4-MUO incorporated within the poly(n-butyl acrylate) microspheres. It should be stressed that due to the nature of both: polymer used to prepare microspheres as well as proteins presents in sample (BSA/enzyme) one can expect competitive accumulation of BSA and enzyme on the surface of microspheres. This, in the case of presence of both BSA and enzyme in sample, can result in apparent decreased activity of enzyme, due to hindered enzyme access to the substrate incorporated within the microsphere. As it can be seen in Figure 5, on the contrary to expectations and literature reports, we have observed that increase of concentration of BSA in sample solution is leading to increase of intensity of fluorescence emission for BSA concentration in sample up to $1.3 \mathrm{mg} / \mathrm{ml}$. Further increase in BSA contents (up to $3.5 \mathrm{mg} / \mathrm{ml}$ ) did not affect measured fluorescence intensity (decrease of signal was not observed). This result is clearly promising from the analytical applications point of view. It is interesting to speculate on the origin of this effect. One of the possibilities is that BSA used contains impurities that act as lipase activators. The enhancement of lipase activity by calcium ions has been widely described [27-30]. The effect of calcium ions is generally assigned to precipitation of calcium salts of fatty acids released in the enzymatic hydrolysis, therefore avoiding product inhibition. Moreover, calcium ions stabilize spatial structure of enzyme by bridging the active site region to the second 


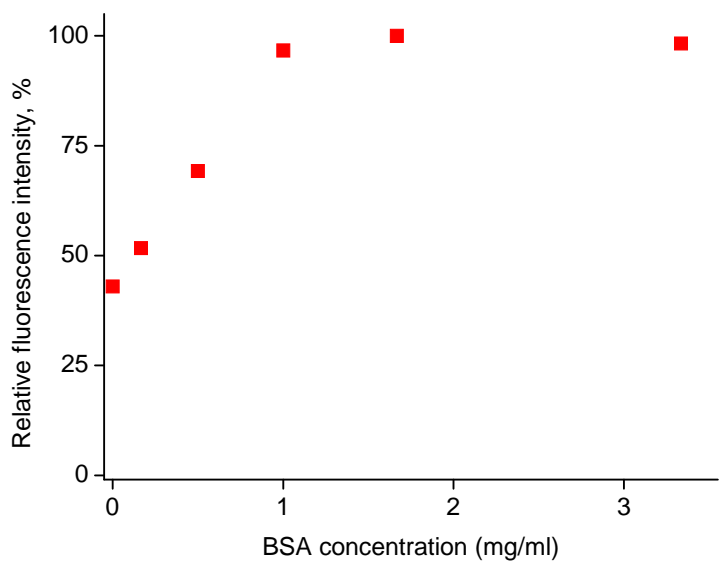

(a)

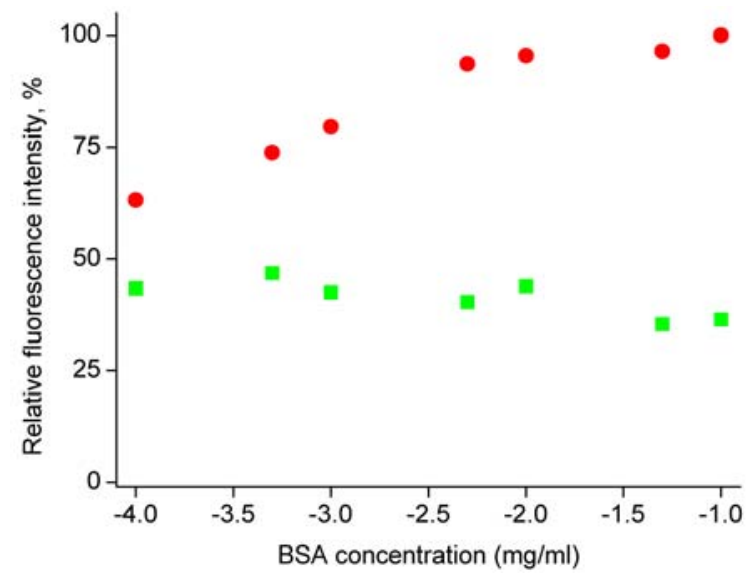

(b)

Figure 5. Effect of a) ( $\square$ ) BSA and b) (○) $\mathrm{Ca}^{2+}$ ions, ( $\left.\square\right) \mathrm{Na}^{+}$ ions on microspheres response. Fluorescence intensity was determined at $\lambda_{\mathrm{em}}=450 \mathrm{~nm}$ following 40 min contact of microspheres with metal ions or BSA, sample volume $300 \mu \mathrm{l}$, lipase activity in solution $0.0185 \mathrm{U} / \mathrm{ml}$.

subdomain of the protein [31].

As it can be seen in Figure 5, introduction of calcium ions to the sample resulted in increase of fluorescence intensity; however, the effect of calcium ions presence is significantly lower compared to the effect of BSA (although relatively high $\mathrm{Ca}^{2+}$ concentration compared to BSA contents was introduced to the sample). It should be also stressed that sodium ions introduced to the sample did not change the fluorescence intensities resulting from enzymatic hydrolysis of 4-MUO.

The effect of addition of calcium chloride $\left(10^{-2}\right.$ $\left.\mathrm{mol} / \mathrm{dm}^{3}\right)$ or BSA $(1.8 \mathrm{mg} / \mathrm{ml})$ to the samples of different lipase activity is shown in Figure 6. As it can be seen in Figure 6, introduction of calcium ions as well as the presence of BSA in the samples has a pronounced effect on recorded fluorescence intensities, in both cases higher values are recorded in the presence of additives. However, in accordance with results presented in Figure 5, Figure $\mathbf{6}$ clearly shows that addition of calcium ions to

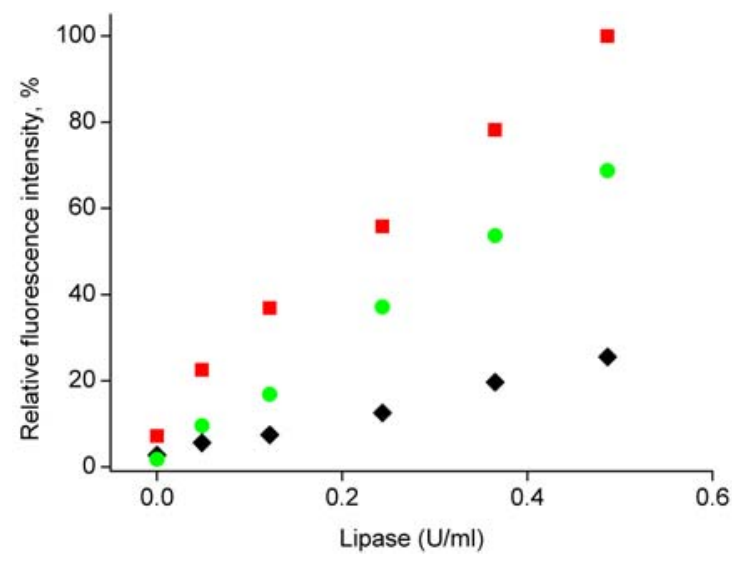

Figure 6. Calibration curves obtained with the use of poly(nbutyl acrylate) microspheres loaded with 4-MUO from solution containing $1.8 \mathrm{mg} / \mathrm{ml}$ of substrate. Fluorescence intensity was measured at $\lambda_{\mathrm{em}}=450 \mathrm{~nm}$ following $40 \mathrm{~min}$ contact of microspheres with $(\diamond)$ lipase solutions, $(\odot)$ lipase solutions spiked with 10 - 2 M CaCl2 solution, (घ) lipase solutions spiked with $1.67 \mathrm{mg} / \mathrm{ml}$ BSA solution.

the sample has significantly lower effect on lipase activeity while reacting with microspheres compared to BSA. It should be also stressed that total calcium level used in BSA (used to perform experiments described) (ICP MS, results not shown) is lower than $0.33 \mathrm{mg} / \mathrm{mg}$ of dry BSA thus even lower level of free calcium ions in BSA cannot contribute significantly to observed lipase activity increase.

On the other hand, it can be postulated that BSA molecules are adsorbing on the surface of microspheres. Thus BSA molecules can create a lipase favorable environment and/or can further protect enzyme from unfavorable conformational change, alternatively helping to preconcentrate the enzyme on the microsphere surface leading ultimately to higher enzyme activity. Most possibly introduction of calcium ions can further increase the observed effect.

An interesting conclusion on the mechanism of BSA beneficial effect on lipase activity determination with 4-MUO loaded microspheres can be driven from change of spheres size and zeta potential. These experiments were performed in solutions for as prepared microspheres, microspheres followed contact with water/THF mixture solution of 4-MUO, or yet followed contact with BSA solution of different concentration. The results of size change studies showed that incorporation of 4-MUO from water/THF mixture is leading to some increase of particle diameter from ca $1500 \mathrm{~nm}$ to $1800 \mathrm{~nm}$. This effect can be attributed to particle swelling due to contact with water/THF mixture. Further contact with BSA solution, regardless BSA contents, and/or lipase did not affect the size of polymeric microsphere substantially. Thus the effect of microsphere size change (and related change in particle surface area) are rather small and 
hardly can contribute to substantial effect of observed increase in sensitivity of 4-MUO loaded microspheres aided enzyme activity determination in the presence of BSA.

However, contact of microsphere with BSA in solution is leading to significant change of its zeta potential, Figure 7. As prepared microspheres or microspheres loaded with 4-MUO have significant negative zeta potential close to $-5 \mathrm{mV}$. However, contact with BSA solution in the presence of TRIS buffer, is leading to significant change in microspheres potential, which becomes significantly higher reaching $+1 \mathrm{mV}$. Similar effect of increase of the microspheres zeta potential to positive values was observed also for other concentrations of BSA in solution (1, 1.6 and $3.3 \mathrm{mg} / \mathrm{ml}$, respectively) (results not shown). This effect is interesting taking into account that isoelectric point of BSA is equal to 4.7 at $25^{\circ} \mathrm{C}$ [32]. Thus in the presence of TRIS buffer of $\mathrm{pH}=7.6 \mathrm{BSA}$ molecule is characterized with negative charge, despite this it is clearly effectively modifying surface of poly(nbutyl acrylate) microsphere. Taking into account the charge of BSA molecule and the potential of microsphere, it seems possible that the interaction is driven by lipophilicity of the sphere. As a result, the potential of microsphere is drastically changed, making its surface significantly more attractive for lipase molecule. It should be stressed that lipase in TRIS buffer solution of $\mathrm{pH} 7.6$ has the negative charge, as its izolectrical point is equal to 5.18 [33]. In effect of enhanced affinity of lipase to the BSA modified microspheres the rate of enzymatic hydrolysis of substrate incorporated in the microspheres is increased leading to higher sensitivity of 4-MUO in microspheres. Thus incorporation of enzyme substrate in microspheres is not only resulting in prevention of oc-

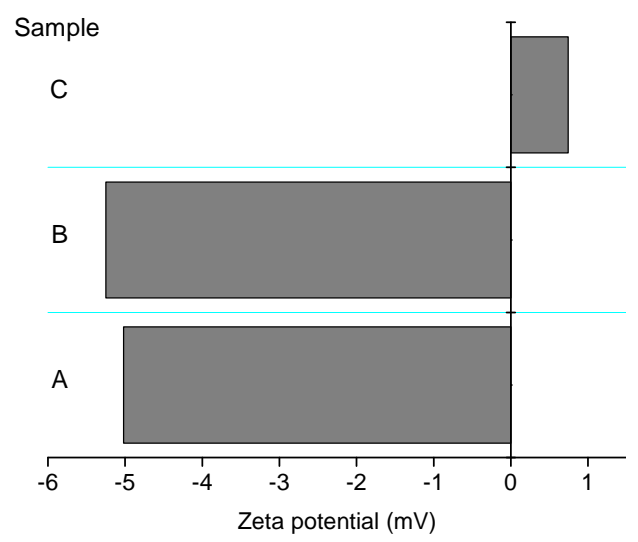

Figure 7. Zeta potential determined for microspheres A) polymerized microspheres (as used for introduction of substrate, i.e. before contact with water/THF mixture); B) loaded with 4-MOU from solution containing $1.8 \mathrm{mg} / \mathrm{ml}$ of substrate; C) microspheres loaded with 4-MOU from solution containing $1.8 \mathrm{mg} / \mathrm{ml}$ of substrate, then left in contact with BSA $0.5 \mathrm{mg} / \mathrm{ml}$ for 40 minutes. currence of unwanted spontaneous deterioration of 4MUO but also microspheres can be modified with proteins to enhance the sensitivity of determination, creating enzyme friendly microenvironment.

\section{Conclusion}

The possibilities of the encapsulation of the hydrolysis susceptible enzymatic substrate within polymeric microspheres to prevent spontaneous, non-enzymatic, hydrolysis were explored. It was shown that introduction of substrate into the microspheres is not affecting enzymatic hydrolysis, resulting in the formation of highly fluorescent 4-methylumbelliferone upon contact with lipase in solution. Changing the amount of substrate incorporated into the sensitivity and rate of enzymatic reaction can be controlled, without the risk of unwanted substrate inhibition. It was shown that further tuning of the enzymatic reaction is possible due to introduction of calcium ions as enzyme activator, or due to the presence of BSA in the sample solution. Despite of the negative charge BSA, molecules were shown to be absorbed on the surface of microspheres leading to a favorable change of its potential from negative to neutral/positive value. Thus, enhancing the contact between the substrate present in microspheres and negatively charged (under experimental conditions) lipase molecules leads to significant enhancement of sensitivity of determination.

\section{Acknowledgements}

This work has been supported by the European Union in the framework of Regional Development Fund through the Joint University of Warsaw and Warsaw University of Technology International PhD Program of Foundation for Polish Science- - "Towards Advanced Functional Materials and Novel Devices" (MPD/2010/4).

\section{REFERENCES}

[1] M. Roberts, "Hydrolysis of 4-Methylumbelliferyl Butyrate: A Convenient and Sensitive Fluorescent Assay for Lipase Activity," Lipids, Vol. 20, No. 4, 1985, pp. $243-$ 247. doi:10.1007/BF02534195

[2] R. S. Sparkes, S. Targum, E. Gershon, G. F. Sensabaugh, M. C. Sparkes and M. Crist, "Evidence for a Null Allele at the Esterase D (EC 3.1.1.1) Locus," Human Genetics, Vol. 46, No. 3, 1979, pp. 319-323. doi:10.1007/BF00273315

[3] E. Nyfeler, J. Grognux, D. Wahler and J.-L. Reymond, "A Sensitive and Selective High-Throughput Screening Fluorescence Assay for Lipases and Esterases," Helvetica Chimica Acta, Vol. 86, No. 8, 2003, pp. 2919-2927. doi: $10.1002 /$ hlca.200390240

[4] S. Peper and E. Bakker, "Fluorescent Ion-Sensing Microspheres for Multiplexed Chemical Analysis of Clinical and Biological Samples," Sensor Update, Vol. 13, No. 1, 
2004, pp. 83-104. doi:10.1002/seup.200390014

[5] D. Westover, W. R. Seitz and B. K. Lavine, "Synthesis and Evaluation of Nitrated Poly(4-hydroxystyrene) Microspheres for pH Sensing," Microchemical Journal, Vol. 74, No. 2, 2003, pp.121-129. doi:10.1016/S0026-265X(02)00178-9

[6] K. Wyglądacz and E. Bakker, "Imaging Fiber Microarray Fluorescent Ion Sensors Based on Bulk Optode Microspheres," Analytica Chimica Acta, Vol. 532, No. 1, 2005, pp. 61-69. doi:10.1016/j.aca.2004.10.071

[7] V. Bychkova and A. Shvarev, "Fabrication of Micrometer and Submicrometer-Sized Ion-Selective Optodes vis a Solvent Displacement Process," Analytical Chemistry, Vol. 81, No. 6, 2009, pp. 2325-2331. doi:10.1021/ac8024619

[8] M. Bradley, L. Alexander, K. Duncan, M. Chennaoui, A. C. Jones and R. M. Sánchez-Martín, "pH Sensing in Living Cells Using Fluorescent Microspheres," Bioorganic \& Medicinal Chemistry Letters, Vol. 18, No. 1, 2008, pp. 313-317. doi:10.1016/j.bmcl.2007.10.075

[9] H. A. Clark, R. Kopelman, R. Tjalkens and M. A. Philbert, "Optical Nanosensors for Chemical Analysis inside Single Living Cells Part 2: Sensors for $\mathrm{pH}$ and Calcium and the Intracellular Application of PEBBLE," Analytical Chemistry, Vol. 71, No. 21, 1999, pp. 4837-4843. doi:10.1021/ac990630n

[10] H. A. Clark, M. Hoyer, M. A. Philbert and R. Kopelman, "Optical Nanosensors for Chemical Analysis inside Single Living Cells Part 1: Fabrication, Characterization and Methods for Intracellular Delivery," Analytical Chemistry, Vol. 71, No. 21, 1999, pp. 4831-4836. doi:10.1021/ac990629o

[11] E. J. Park, M. Brausel, C. Behrand, M. A. Philbert and R. Kopelman, "Ratiometric Optical PEBBLE Nanosensors for Magnesium Ions in Viable Cells," Analytical Chemistry, Vol. 75, No. 15, 2003, pp.3784-3791. doi: $10.1021 / \mathrm{ac} 0342323$

[12] W. Tang, H. Xu, E. J. Park, M. A. Philbert and R. Kopelman, "Encapsulation of Methylene Blue in Polyacrylamide Nanoparticle Platforms Protects Its Photodynamic Effectiveness," Biochemical and Biophysical Research Communications, Vol. 369, No. 2, 2008, pp. 579583. doi:10.1016/j.bbrc.2008.02.066

[13] J. P. Sumner, J. W. Aylott, E. Monson and R. Kopelman, "A Fluorescent PEBBLE Nanosensor for Intracellular Free Zinc.” Analyst, Vol. 127, No. 1, 2002, pp. 11-16. doi:10.1039/b108568a

[14] K. L. Brogan and D. R. Walt, "Optical Fiber-Based Sensors: Application to Chemical Biology," Current Opinion in Chemical Biology, Vol. 9, No. 5, 2005, pp. 494-500. doi:10.1016/i.cbpa.2005.08.009

[15] A. Michalska and E. A. H. Hall, "Fluorescent Polymeric Spheres for Alkaline Phosphatase Sensing," Presentation at Pittcon 2009 Conference, 2009.

[16] M. J. Ruedas-Rama and E. A. H. Hall, "K'-Selective Nanospheres: Maximising Response Range and Minimising Response Time," Analyst, Vol. 131, No. 12, 2006, pp. 1282-1291. doi:10.1039/b608901a

[17] L. Y. Heng, K. Toth and E. A. H. Hall, "Ion-Transport and Diffusion Coefficients of Non-Plasticized Methacrylic-Acrylic Ion-Selective Membranes," Talanta, Vol. 63, No. 1, 2004, pp. 73-87. doi:10.1016/j.talanta.2003.12.051

[18] A. Michalska, M. Wojciechowski, E. Bulska and K. Maksymiuk, "Quantifying Primary Silver Ions Contents in Poly(vinyl chloride) and Poly(n-butyl acrylate) Ion-Selective Membranes." Electroanalysis, Vol. 21, No. 17-18, 2009, pp. 1931-1938. doi:10.1002/elan.200804611

[19] B. Figureurska and J. Pluta, "Badanie Dostępności Farmaceutycznej Kreonu ${ }^{\circledR}$ Neo-Pancreatinum i Panzytratu," Advances in Clinical and Experimental Medicine, Vol. 13, No. 5, 2004, pp. 779-787.

[20] T. de Laborde de Monpezat, B. de Jeso, J.-L. Butour, L. Chavant and M. Sancholle, "A fluorimetric Method for Measuring Lipase Activity," Lipids, Vol. 25, No. 10, 1990, pp. 661-664. doi:10.1007/BF02536018

[21] D. Martin, J. Ruiz, M. Flores and F. Toldra, "Effect of Dietary Conjugated Linoleic Acid and Monounsaturated Fatty Acid Content on Pig Muscle and Adipose Tissue Lipase and Esterase Activity," Journal of Agricultural and Food Chemistry, Vol. 54, No. 24, 2006, pp. 92419247. doi: $10.1021 /$ if $061765 \mathrm{e}$

[22] B. Borgström and C. Erlanson, "Interactions of Serum Albumin and Other Proteins with Porcine Pancreatic Lipase," Gastroenterology, Vol. 75, No. 3, 1978, pp. 382386.

[23] Y. Gargouri, G. Pieroni, C. Riviere, A. Sugihara, L. Sandra and R. Verger, "Inhibition of Lipases by Proteins, a Kinetic Study with Dicaprin Monolayers," The Journal of Biological Chemistry, Vol. 260, No. 4, 1985, pp. 22682273.

[24] H. Chahinian, S. Bezzine, F. Ferrato, M. G. Ivanova, B. Perez, E. M. Lowe and F. Carriere "The $\beta 5$ Loop of the Pancreatic Lipase C2-Like Domain Plays a Critical Role in the Lipase-Lipid Interactions," Biochemistry, Vol. 41, No. 46, 2002, pp. 13725-13735. doi:10.1021/bi0257944

[25] J. C. Khoo, E. J. Vance, E. M. Mahoney, D. Jensen, E. Wancewicz and D. Steinberg, "Neutral Triglyceride Lipase in Macrophages," Artreriosclerosis, Vol. 4, No. 1, 1984, pp. 34-40. doi:10.1161/01.ATV.4.1.34

[26] Z. Sroka, "The Activity of Lipase from Rhizopus sp. in Native Form and after Immobilization on Hollow-Fiber Membranes," Journal of Membrane Science, Vol. 97, 1994, pp. 209-214. doi:10.1016/0376-7388(94)00163-S

[27] N. W. Tietz and D. F. Shuey, "Lipase in Serum-the Elusive Enzyme: An Overview," Clinical Chemistry, Vol. 39, No. 5, 1993, pp. 746-756.

[28] S. S. Kanwar, I. A. Ghazi, S. S. Chimni, G. K. Joshi, G. V. Rao, R. K. Kaushal, R. Gupta and V. Punji, "Purification and Properties of a Novel Extra-Cellular Thermotolerant Metallolipase of Bacillus Coagulants MTCC-6375 Isolate," Protein Expression and Purification, Vol. 46, No. 2, 2006, pp. 421-428. doi:10.1016/j.pep.2005.10.007

[29] K. R. Kim, D. Y. Kwon, S. H. Yoon and W. Y. Kim, "Purification, Refolding, and Characterization of Recombinant Pseudomonas Fluorescens Lipase," Protein Expression and Purification, Vol. 39, No. 1, 2005, pp. 124 129. doi:10.1016/j.pep.2004.09.014 
[30] S. Sabri, R. N. Z. R. A. Rahman, T. L. Leow, M. Basri and A. B. Salleh, "Secretory Expression and Characterization of Highly $\mathrm{Ca}^{2+}$-Activated Thermostable L2 Lipase," Protein Expression and Purification, Vol. 68, No. 2, 2009, pp. 161-166. doi:10.1016/j.pep.2009.08.002

[31] J. D. A. Tyndall, S. Sinchaikul, L. A. Forthergill-Gilmore, P. Taylor and M. D. Walkinshaw, "Crystal Structure of a Thermostable Lipase from Bacillus Stearothermophilus P1," Journal of Molecular Biology, Vol. 323, No. 5, 2002, pp. 859-869. doi:10.1016/S0022-2836(02)01004-5
[32] U. Bohme and U. Scheler, "Effective Charge of Bovine Serum Albumin Determined by Electrophoresis NMR," Chemical Physics Letters, Vol. 435, No. 4-5, 2007, pp. 342-345. doi:10.1016/j.cplett.2006.12.068

[33] J. Donner, "Preparation of Porcine Pancreatic Lipase Free of Co-lipase Activity," Acta Chemica ScandinavicaSeries B, Vol. 30, No. 5, 1976, pp. 430-434.

doi:10.3891/acta.chem.scand.30b-0430 